\title{
Ectoparasite loads in sympatric urban populations of the northern white-breasted and the European hedgehog
}

\author{
Sylwia Dziemian • Bożena Sikora • Barbara Pilacińska • \\ Jerzy Michalik • Rafal Zwolak
}

Received: 27 January 2015 / Accepted: 6 March 2015 / Published online: 29 March 2015

(C) The Author(s) 2015. This article is published with open access at Springerlink.com

\begin{abstract}
We investigated abundance and prevalence of ticks and fleas infesting urban populations of two species of hedgehogs: the northern white-breasted hedgehog (Erinaceus roumanicus) and the European hedgehog (Erinaceus europaeus). The hedgehogs were captured in the city of Poznań (western Poland) over the period of 4 years. Both species of hedgehogs were infested with the castor bean tick (Ixodes ricinus), the hedgehog tick (Ixodes hexagonus), and the hedgehog flea (Archeopsylla erinacei). The northern whitebreasted hedgehog had higher loads of I. ricinus and A. erinacei than the European hedgehog. The abundance and prevalence of $I$. hexagonus were similar on both species of hosts. Co-infestation with the two species of ticks was more frequent on the northern white-breasted hedgehog than on the European hedgehog. Therefore, these two closely related species of hedgehogs differ in their importance as hosts of arthropod vectors of pathogens in urban areas and might play a different role in the dynamics of zoonotic diseases.
\end{abstract}

Keywords Ectoparasites $\cdot$ Erinaceus europaeus $\cdot$ Erinaceus roumanicus $\cdot$ Fleas $\cdot$ Hedgehogs $\cdot$ Ticks

\section{Introduction}

Ticks (Acari) and fleas (Siphonaptera) are among the most important hematophagous ectoparasites of terrestrial

\footnotetext{
S. Dziemian • B. Piłacińska $\cdot$ R. Zwolak $(\bowtie)$

Department of Systematic Zoology, Faculty of Biology, Adam Mickiewicz University, Umultowska 89, 61-614 Poznań, Poland e-mail: rzwolak@amu.edu.pl

B. Sikora $\cdot$ J. Michalik

Department of Animal Morphology, Faculty of Biology, Adam

Mickiewicz University, Poznań, Poland
}

vertebrates and vectors of zoonotic disease. During their blood meals, they might transmit various pathogens such as viruses, bacteria, and protozoa that can infect animals and humans (Beugnet and Marié 2009; Sobrino et al. 2012). The increase in the incidence of flea- and tick-borne zoonotic diseases is facilitated by the development of extensive urban and suburban areas with gardens, parks, and other green spaces. This process provides suitable habitat for wild hosts of arthropod vectors, bringing humans and disease-transmitting arthropods in proximity and increasing the risk of infections (Patz et al. 2004; Beugnet and Marié 2009).

Hedgehogs (Erinaceus sp.) are a prominent example of wild animals that thrive in urban areas, are infested by ticks and fleas, and might facilitate infection of humans and their pets with zoonotic microorganisms (Riley and Chomel 2005; Hubert et al. 2011; Poel et al. 2015). Urban environment is often characterized by impoverished fauna. In particular, it lacks large vertebrates such as cervids, which serve as hosts for most of the adult ticks (Dautel and Kahl 1999). The insufficient availability of suitable hosts might often be a major factor restricting the occurrence of ticks in towns (Dautel and Kahl 1999). However, all developmental stages of many ticks feed on medium-sized mammals such as hedgehogs (Pfäffle et al. 2011; Dziemian et al. 2014). Moreover, hedgehogs are known to be very heavily infested with ticks and fleas (Gaglio et al. 2010; Földvári et al. 2011). Therefore, these mammals play an important role in the maintenance of zoonotic agents within urban areas (Dautel and Kahl 1999; Pfäffle et al. 2014).

Northern white-breasted hedgehogs (Erinaceus roumanicus) and European hedgehogs (Erinaceus europaeus) often co-occur in urban areas within their central European contact zone, which runs from central Scandinavia through western Poland, central and eastern Moravia, western and central Austria to western Slovenia, and Italy (Lapini 1999). Until 1967, the European hedgehog and the northern whitebreasted hedgehog were not recognized as separate species, 
and even currently, very little is known about possible differences in their biology (Kral 1967). The research gaps include potential differences in ectoparasite infestation patterns between the two hedgehog species. Such studies are needed to evaluate the role of these mammals in the circulation of zoonotic diseases. The Europaean hedgehog is known to harbor several tick-borne pathogens such as Borrelia burgdorferi s.l. and Anaplasma phagocytophilum, and flea-borne pathogens like Yersinia pseudotuberculosis (Keymer et al. 1991; Gray et al. 1994; Gern et al. 1997; Skuballa et al. 2007; Skuballa et al. 2010). Data on the northern white-breasted hedgehog are scarce, but it is known to maintain TBE virus and, recently, it has been found to be a potential reservoir of Lyme disease spirochetes (Kožuch et al. 1967; Skuballa et al. 2012). Furthermore, urban populations of this hedgehog species are infected with Candidatus Neoehrlichia mikurensis and A. phagocytophilum (Földvári et al. 2014). The latter was also detected in castor bean ticks, Ixodes ricinus, removed from northern white-breasted hedgehogs in Romania and Hungary (Dumitrache et al. 2013; Földvári et al. 2014). Moreover, the hedgehog flea (Archaeopsylla erinacei), which infests both E. europaeus and E. roumanicus, was found to host Ricketsia felis, Bartonella clarridgeiae, and Bartonella elizabethae (Bitam et al. 2006; Gilles et al. 2009; Bitam et al. 2010; Hornok et al. 2014).

In general, hosts that are taxonomically related and ecologically similar are likely to share parasite species and thus have the potential of hosting similar pathogens (Bitam et al. 2010). However, we do not know if parasite loads of sympatric populations of the two hedgehog species differ. Research on ectoparasites of E. roumanicus and E. europaeus were conducted in areas of allopatry or focused on only one of these species (Gray et al. 1994; Reeve 1994; Pfäffle et al. 2009; Thamm et al. 2010; Földvári et al. 2011; Dziemian et al. 2014; Hajipour et al. 2014). Alternatively, inferences were based on ectoparasites collected from dead animals provided by wildlife rescue centers (Pfäffle et al. 2014). As a consequence, reliable comparisons of ectoparasite loads in E. roumanicus and E. europaeus are currently non-existent. Here, we describe patterns of ectoparasite infestation of both hedgehogs species co-occurring in the city of Poznan in western Poland. To our knowledge, this is the first study of ectoparasites of living hedgehogs in sympatric populations of E. roumanicus and E. europaeus.

\section{Materials and methods}

Poznań $\left(52^{\circ} 17^{\prime} 34^{\prime \prime} \mathrm{N}, 16^{\circ} 44^{\prime} 08^{\prime \prime} \mathrm{E}\right)$ is a city in western Poland with a population of 551,600 people and area of $262 \mathrm{~km}^{2}$. The hedgehogs were captured regularly within three residential areas: BON (60 ha), SOB (54 ha), and TYS (48 ha). They have also been caught haphazardly in a few areas and pooled into category "other" (OTH) or rescued from drainage ditches stretching along Poznan's Fast Tram (PST) line. Hedgehog trapping was conducted from 2009 to 2012 throughout the period of hedgehog activity (March-November) by walking on established transects within the residential areas, starting at sunset and lasting until 23:00 to 2:00. Hedgehogs were located with flashlights and captured by hand. Checkups of drainage ditches along PST were performed two to three times per week during morning hours (8:00-10:00).

Captured hedgehogs were taken to the laboratory, were kept overnight in individual boxes $(37 \times 47 \times 26 \mathrm{~cm})$, and received commercial cat food and water ad libitum. In the morning, the animals were weighted, sexed, and placed on a white sheet of paper and visually examined for ectoparasites. The examination was usually performed by two cooperating researchers and lasted from $15 \mathrm{~min}$ to $2 \mathrm{~h}$, depending on the degree of infestation and behavior of the animal. Some individuals did not unroll and were not included in the analyses. Hedgehogs were individually marked (with color-coded and numbered plastic tubes glued to spines) before releasing in the following evening in the exact place of capture (or, in case of PST, $100 \mathrm{~m}$ away from the ditches). In total, we examined 296 hedgehogs: 46 European hedgehogs (12 females and 34 males) and 250 northern white-breasted hedgehogs (120 females and 130 males), with 3 recaptures of the European hedgehog and 46 recaptures of the northern white-breasted hedgehog giving total sample size of 327. Catching and handling procedures of hedgehogs were approved by the appropriate Institutional Animal Care and Use Committees (permission no. DOPog-4201-03-158/03/al.). All fleas and feeding ticks found on hedgehogs were removed with tweezers and stored in $70 \%$ alcohol. In addition, each box in which an animal was kept was examined for the presence of detached ticks. Ticks and fleas were counted and identified under a microscope using standard keys (Arthur 1963; Skuratowicz 1967; Siuda 1993). All ticks belonged to two species: the hedgehog tick, Ixodes hexagonus, and the castor bean tick, I. ricinus, and almost all fleas were identified as the hedgehog flea $A$. erinacei. Other fleas (six individuals of Nosopsyllus fasciatus, one Ctenophthalmus agyrtes, and one Ctenophthalmus assimilis) were not included in statistical analyses due to their rarity.

For each ectoparasite species, we estimated mean abundance (the number of a parasite species per host: Bush et al. 1997 ) and prevalence (the number of hosts infested with one or more individuals of a parasite: Bush et al. 1997) on both host species. We also compared proportions of E. roumanicus and E. europeaus hosts that were co-infested with both tick species. All analyses were conducted with generalized linear mixed models (GLMMs; Paterson and Lello 2003) implemented via the lme4 package (Bates et al. 2014) in R (R Core Team 2013). In the analysis of parasite abundance, we used Poisson family error terms and a log link function. In the 
analysis of prevalence and tick co-infestation, we used binomial family and logit link function. Predictor variables included fixed effects of host species (E. roumanicus vs. E. europeaus), host sex (male vs. female hedgehogs), and season (grouped as spring, April-May; summer, June-August; and fall, SeptemberNovember). Additionally, in the analyses of tick abundance and prevalence, we controlled for tick stage (female, nymph, or larvae: entered as a fixed effect). The initial models included all possible two-way interactions among the fixed effects. To simplify the initial models, we eliminated in a stepwise fashion all interactions with $P>0.10$.

Random effects included individual hedgehog, year, and study site. In the analyses of prevalence and abundance, random effects also included a unique identifier for each observation, which creates over-dispersed Poisson and binomial models (Zwolak et al. 2013). In the analysis of tick abundance, the effect of tick stage was partly correlated over individual host. However, we did not use this structure in the analyses of prevalence and co-infestation because it did not improve the fit of the models (evaluated with Akaike's information criterion: Burnham and Anderson 2002).

\section{Results}

\section{Ixodes ricinus}

The abundance of I. ricinus was higher in E. roumanicus than in E. europaeus (species effect in Table 1; Fig. 1a) and differed among seasons, with seasonality affected by host sex and tick stage (season, season $\times$ sex, and season $\times$ stage effects in Table 1 ; Table 2). The abundance of I. ricinus was high in spring and declined throughout summer and fall, but this pattern was more pronounced in males (Fig. 1a). Males also carried more ticks than females (sex effect in Table 1). Particular tick stages differed in abundance (stage and season $\times$ stage effects in Table 1; Table 2).

In contrast to its abundance, prevalence of I. ricinus was not affected by the host species (non-significant species effect in Table 1). However, the two hedgehog species differed in the prevalence of I. ricinus on males and females: I. ricinus prevalence was more biased toward males in E. europaeus than in E. roumanicus (sex and species $\times$ sex effects in Table 1; Fig. 1b). Similarly to the abundance, prevalence of I. ricinus differed among particular seasons and tick stages (season, stage, and season $\times$ stage effects in Table 1).

\section{I. hexagonus}

In the case of $I$. hexagonus, patterns of abundance and prevalence were very similar and did not differ between $E$. roumanicus and E. europaeus (non-significant species effect in Table 1). Both abundance and prevalence of I. hexagonus were higher for male than for female hosts and differed among particular tick stages
Table 1 Factors influencing abundance and prevalence of ticks (Ixodes ricinus and Ixodes hexagonus) and fleas (Archaeopsylla erinacei) infesting northern white-breasted hedgehogs (Erinaceus roumanicus) and European hedgehogs (Erinaceus europaeus) in urban environment in the city of Poznań, Poland

\begin{tabular}{|c|c|c|c|c|c|c|}
\hline \multirow[t]{2}{*}{ Variable $^{\mathrm{a}}$} & \multicolumn{3}{|c|}{ Abundance } & \multicolumn{3}{|c|}{ Prevalence } \\
\hline & $x^{2}$ & $\mathrm{df}$ & $P$ & $x^{2}$ & $\mathrm{df}$ & $P$ \\
\hline \multicolumn{7}{|l|}{ (a) Ixodes ricinus } \\
\hline Species & 6.04 & 1 & 0.014 & 2.04 & 1 & 0.153 \\
\hline Season & 79.47 & 2 & $<0.001$ & 35.22 & 2 & $<0.001$ \\
\hline Sex & 37.06 & 1 & $<0.001$ & 14.91 & 1 & $<0.001$ \\
\hline Stage & 110.94 & 2 & $<0.001$ & 76.06 & 2 & $<0.001$ \\
\hline Species $\times$ sex & - & - & - & 3.69 & 1 & 0.055 \\
\hline Season $\times$ sex & 6.89 & 2 & 0.032 & - & - & - \\
\hline Season $\times$ stage & 59.37 & 4 & $<0.001$ & 57.90 & 4 & $<0.001$ \\
\hline \multicolumn{7}{|l|}{ (b) Ixodes hexagonus } \\
\hline Species & 2.05 & 1 & 0.152 & 1.92 & 1 & 0.166 \\
\hline Season & 6.46 & 2 & 0.040 & 6.07 & 2 & 0.048 \\
\hline Sex & 10.15 & 1 & 0.001 & 8.66 & 1 & 0.003 \\
\hline Stage & 32.88 & 2 & $<0.001$ & 24.90 & 2 & $<0.001$ \\
\hline Season $\times$ sex & 25.16 & 2 & $<0.001$ & 24.38 & 2 & $<0.001$ \\
\hline \multicolumn{7}{|c|}{ (c) Archaeopsylla erinacei } \\
\hline Species & 9.98 & 1 & 0.002 & 11.31 & 1 & $<0.001$ \\
\hline Season & 22.30 & 2 & $<0.001$ & 22.13 & 2 & $<0.001$ \\
\hline Sex & 3.60 & 1 & 0.058 & 2.45 & 1 & 0.118 \\
\hline Species $\times$ season & 5.90 & 2 & 0.052 & - & - & - \\
\hline
\end{tabular}

\footnotetext{
a "Species" denotes host species (E. roumanicus and E. europaeus), "season" represents season of the year (spring, summer, autumn), "sex" represents sex of the host, and "stage" denotes tick stage (larva, nymph, female). See the "Materials and methods" section for further explanations
}

(significant sex and stage effects in Table 1; Table 2). The main effect of season on I. hexagonus infestation patterns was statistically significant, but weak (Table 1 and Fig. 1c, d). However, there were marked differences in seasonality of infestation between male and female hosts (Table 1): infestation of male hosts was high in spring and summer, and infestation of females was high in spring and fall (Fig. 1c, d).

\section{Co-infestation with I. ricinus and I. hexagonus}

Simultaneous infestation with both tick species occurred more often on E. roumanicus than on E. europaeus (odds ratio $\chi^{2}=$ $4.78, \mathrm{df}=1, P=0.029$ ) and varied with seasons. It was highest in spring, intermediate in summer, and lowest in autumn $\left(\chi^{2}=\right.$ $19.98, \mathrm{df}=2, P<0.001)$. In addition, co-infestation was marginally more frequent in males than in females $\left(\chi^{2}=3.30, \mathrm{df}=1, P=\right.$ 0.069). Taking all these factors into account, the probability of co-infestation varied from $11 \%$ (females in the fall) to $51 \%$ (males in the spring) in E. europaeus and from $23 \%$ (females in the fall) to $71 \%$ (males in the spring) in E. roumanicus. 

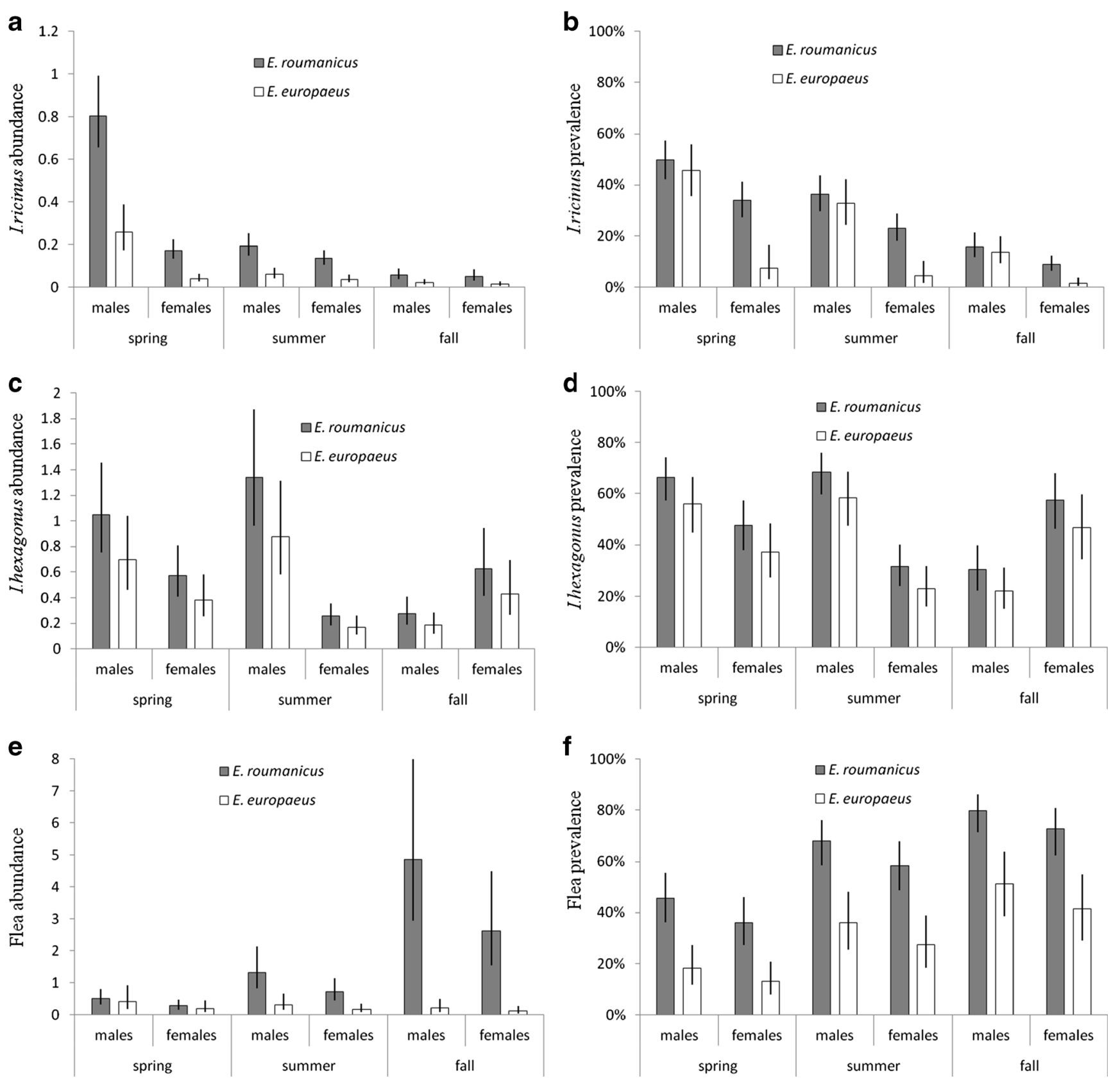

Fig. 1 Abundance and prevalence of ectoparasites infesting the northern white-breasted hedgehog (Erinaceus roumanicus) and the European hedgehog in the city of Poznań, Poland: a abundance of Ixodes ricinus, b prevalence of $I$. ricinus, $\mathbf{c}$ abundance of $I$. hexagonus, $\mathbf{d}$ prevalence of

I. hexagonus, e abundance of Archaeopsylla erinacei, and $\mathbf{f}$ prevalence of A. erinacei. Estimates are provided separately for male and female hosts and are presented with standard errors

\section{A. erinacei}

Flea abundance and prevalence were higher for E. roumanicus than for E. europaeus (species effect in Table 1c; Fig. 1e, 1f). Both abundance and prevalence of fleas differed among seasons (Table 1). In addition, the seasonal patterns of flea abundance marginally differed between the two hedgehog species (species $\times$ season interaction in Table 1 ), with flea abundance increasing from spring to fall in E. roumanicus, but not in

E. europaeus (Fig. 1e, f). Finally, flea abundance was marginally higher in male hosts, regardless of hedgehog species (sex effect in Table 1).

\section{Discussion}

Although northern white-breasted hedgehogs and European hedgehogs have similar biology and appear to share the same 
Table 2 Seasonal changes in the abundance of tick stages infesting northern white-breasted and European hedgehogs (Erinaceus roumanicus and Erinaceus europaeus, respectively) in urban environment in the city of Poznan, Poland

\begin{tabular}{|c|c|c|c|c|c|c|}
\hline & \multicolumn{3}{|l|}{ E. roumanicus } & \multicolumn{3}{|l|}{ E. europaeus } \\
\hline & Spring & Summer & Fall & Spring & Summer & Fall \\
\hline \multicolumn{7}{|l|}{ (a) I. ricinus } \\
\hline Larvae & $0.01(0.00-0.04)$ & $0.07(0.03-0.19)$ & $0.02(0.01-0.09)$ & $0.01(0.00-0.02)$ & $0.03(0.01-0.11)$ & $0.01(0.00-0.04)$ \\
\hline Nymphs & $1.28(0.71-2.29)$ & $0.47(0.22-0.99)$ & $0.11(0.05-0.26)$ & $0.46(0.21-0.99)$ & $0.23(0.09-0.59)$ & $0.05(0.02-0.15)$ \\
\hline Females & $0.96(0.51-1.79)$ & $0.13(0.07-0.26)$ & $0.06(0.03-0.14)$ & $0.47(0.20-1.11)$ & $0.06(0.03-0.16)$ & $0.03(0.01-0.09)$ \\
\hline \multicolumn{7}{|c|}{ (b) I. hexagonus } \\
\hline Larvae & $0.51(0.26-1.00)$ & $0.35(0.18-0.66)$ & $0.28(0.13-0.57)$ & $0.36(0.16-0.83)$ & $0.27(0.12-0.61)$ & $0.20(0.08-0.47)$ \\
\hline Nymphs & $1.50(0.85-2.64)$ & $1.01(0.58-1.76)$ & $0.76(0.39-1.46)$ & $1.03(0.49-2.16)$ & $0.70(0.32-1.54)$ & $0.56(0.25-1.23)$ \\
\hline Females & $0.71(0.40-1.25)$ & $0.49(0.28-0.86)$ & $0.38(0.20-0.73)$ & $0.49(0.23-1.05)$ & $0.34(0.16-0.73)$ & $0.28(0.13-0.61)$ \\
\hline
\end{tabular}

Estimates were obtained with generalized linear mixed models (see the "Materials and methods" section) and are presented with $95 \%$ confidence intervals

species of ectoparasites (Reeve 1994; Sommer 2007; Gaglio et al. 2010; Földvári et al. 2011; Pfäffle et al. 2014), we found that ectoparasite burdens of sympatric populations of these two species are different. E. roumanicus carried more I. ricinus ticks and A. erinacei fleas than E. europaeus. On the other hand, the two hedgehog species did not differ in I. hexagonus infestation parameters. These results complement a study by Pfäffle et al. (2014), who reported that E. roumanicus and E. europaeus in their contact zone in Czech Republic differed in the abundance of intestinal endoparasites.

Interspecific differences in parasite load depend on many behavioral, ecological, and physiological factors. Infestation with parasites might be influenced, e.g., by the density of host population (Anderson and May 1979; Arneberg 2001; Krasnov et al. 2002; Brunner and Ostfeld 2008), social organization (Altizer et al. 2003; Monello and Gompper 2010), variation in parasite densities within home range (Calabrese et al. 2011), host diet composition (Ezenwa 2004; NavarroGonzalez et al. 2011), habitat associations (Thamm et al. 2010), and differences in immunological systems (Keesing et al. 2009). However, comparative studies on these aspects of biology of E. roumanicus and E. europaeus are virtually non-existent, highlighting a gap in our knowledge. In particular, much less is known about E. roumanicus than E. europaeus. Therefore, discussion of the causes of differences in infestation patterns found in E. roumanicus and E. europaeus must be largely speculative.

I. ricinus tick is a generalist exophilic species, questing for its hosts on vegetation. Therefore, its off-host activity in urban environment is restricted to relatively few areas with high vegetation cover and humidity, such as parks, gardens, or cemeteries (Dautel and Kahl 1999). Thus, it is possible that the difference between E. roumanicus and E. europaeus in infestation with $I$. ricinus is related to the differential use of the urban habitat by the two host species. For example,
E. roumanicus could have larger homer ranges or select more heavily vegetated habitats than E. europeaus. However, so far, there have been no studies on home range size or habitat selection in E. roumanicus. Moreover, the two hedgehog species differed in the abundance, but not prevalence, of I. ricinus. Such pattern suggests another underlying mechanism. Interspecific differences in body mass cannot explain the differences in tick abundances, because individuals of E. europaeus were slightly heavier, on average, than individuals of E. roumanicus (mean and standard deviation, $926 \pm 257$ vs. $722 \pm 256 \mathrm{~g}$ ); thus, we would expect an opposite pattern. Another alternative is that E. europaeus is more resistant to I. ricinus than E. roumanicus and therefore is able to keep infestation at lower levels (Råberg et al. 2009). Resistance to ticks is an important factor that influences the intensity of infestation (Wikel 1996), and this trait can vary greatly among different species or even breeds of animals (Fielden et al. 1992; Piper et al. 2010).

We found no differences between the two hedgehog species in the abundance and prevalence of $I$. hexagonus. In contrast to I. ricinus, I. hexagonus specializes on hedgehogs and has a nidicolous lifestyle: it inhabits nests of its host, where it reproduces, and attaches to the host when taking a blood meal. Because of this life history and frequent use of various types of nests by hedgehogs (reproductive nests, day nests, hibernacula: Reeve 1994), this parasite has nearly constant contact with its host. Infestation levels of $I$. hexagonus might be regulated by density-dependent mechanisms, such as interference competition between larvae within the nests of hosts (Pfäffle et al. 2011). Such mechanism would be largely independent of characteristics of individual host and could explain similar levels of I. hexagonus infestation on E. roumanicus and E. europaeus.

Co-infections with both tick species were found considerably more often in E. roumanicus than in E. europaeus. This pattern indicates that co-feeding transmission of 
pathogens between the two tick species might occur more often on the former species of hedgehog. Even though I. hexagonus does not feed on as many species as I. ricinus, it might be involved in the enzootic subcycle of various pathogens such as Borrelia spp. or A. phagocytophilum. These microorganisms can be acquired by I. hexagonus, can be passed via co-feeding transmission to I. ricinus, and can subsequently infect other wildlife, pets, and humans (Pfäffle et al. 2011).

We do not discuss tick stage results in this study because the two host species did not differ in this regard and such a discussion would make this report considerably longer. The analysis of I. ricinus and I. hexagonus stage dynamics can be found in Pfäffle et al. (2011) (European hedgehog) and Dziemian et al. (2014) (northern white-breasted hedgehog).

The hedgehog flea $A$. erinacei is nidicolous, similarly to I. hexagonus (Morris 1973). However, patterns of the flea infestation resembled rather those of the exophilic I. ricinus, with ectoparasite loads higher on E. roumanicus than on E. europaeus. Nevertheless, in the case of the hedgehog flea, host species strongly influenced both abundance and prevalence of the ectoparasite, and possibly also the seasonal dynamics of infestation levels. While reasons for the differences in flea loads between the two host species are not clear, they indicate that these sister hedgehog species are not as similar in their biology as previously thought (see also Bolfiková and Hulva 2012; Pfäffle et al. 2014).

As a consequence of the reported differences in ectoparasite loads, the two hedgehog species might play a different role in cycling of vector-borne diseases in urban areas. Hosts which are most heavily infested by ticks and fleas are also most likely to be infected by pathogens (Brunner and Ostfeld 2008). Moreover, such hosts are also most likely to subsequently infect numerous naïve ectoparasites. Therefore, gauging interspecific differences in ectoparasite loads is considered to be an essential component in comprehending and controlling the transmission of vectorborne zoonotic disease (Brunner and Ostfeld 2008). However, the maintenance of particular pathogens is also strongly influenced by reservoir competence of wildlife hosts (LoGiudice et al. 2003). Therefore, the reservoir status of urban-adapted animal species such as E. roumanicus and E. europaeus could provide fruitful venues of future research (see, e.g., Levin et al. 2002; Ginsberg et al. 2005; Radzijevskaja et al. 2013). This issue is particularly urgent in the light of ongoing expansion of urban and suburban areas, which become the most important sites of interactions between humans and city-adapted wildlife hosts (Pfäffle et al. 2013).

Acknowledgments We thank Magdalena Chmielewska for identification of fleas. This study was financially supported by the Ministry of Science and Higher Education grant no. N N304 325439.

Open Access This article is distributed under the terms of the Creative Commons Attribution License which permits any use, distribution, and reproduction in any medium, provided the original author(s) and the source are credited.

\section{References}

Altizer S, Nunn CL, Thrall PH, Gittleman JL, Antonovics J, Cunningham AA, Dobson AP, Ezenwa V, Jones KE, Pedersen AB, Poss M, Pulliam JR (2003) Social organization and parasite risk in mammals: integrating theory and empirical studies. Ann Rev Ecol Evol Syst 34:517-547

Anderson RM, May RM (1979) Population biology of infectious diseases: Part I. Nature 280:361-367

Arneberg P (2001) An ecological law and its macroecological consequences as revealed by studies of relationships between host densities and parasite prevalence. Ecography 24:352-358

Arthur DR (1963) British ticks. Butterworths, London

Bates D, Maechler M, Bolker B, Walker S (2014) lme4: Linear mixedeffects models using Eigen and S4. R package version 1.1-7, http:// CRAN.R-project.org/package $=$ lme4. Accessed 26 Jan 2015

Beugnet F, Marié J-L (2009) Emerging arthropod-borne diseases of companion animals in Europe. Vet Parasitol 163:298-305

Bitam I, Parola P, Dittmar de la Cruz K, Matsumoto K, Baziz B, Rolain JM, Belkaid M, Raoult D (2006) First molecular detection of Rickettsia felis in fleas from Algeria. Am J Trop Med Hyg 74:532-535

Bitam I, Dittmar K, Parola P, Whiting MF, Raoult D (2010) Fleas and flea-borne diseases. Int J Infect Dis 14:e667-e676

Bolfiková B, Hulva P (2012) Microevolution of sympatry: landscape genetics of hedgehogs Erinaceus europaeus and E. roumanicus in Central Europe. Heredity 108:248-255

Brunner JL, Ostfeld RS (2008) Multiple causes of variable tick burdens on small mammal hosts. Ecology 89:2259-2272

Burnham KP, Anderson DR (2002) Model selection and multimodel inference: a practical information-theoretic approach. Springer, New York

Bush AO, Lafferty KD, Lotz JM, Shostak AW (1997) Parasitology meets ecology on its own terms: Margolis et al. revisited. J Parasitol 83:575-583

Calabrese JM, Brunner JL, Ostfeld RS (2011) Partitioning the aggregation of parasites on hosts into intrinsic and extrinsic components via an extended Poisson-gamma mixture model. PLoS One 6:e29215

Core Team R (2013) R: A language and environment for statistical computing. R Foundation for Statistical Computing, Vienna

Dautel H, Kahl O (1999) Ticks (Acari: Ixodidea) and their medical importance in the urban environment. Proceedings of the $3 \mathrm{rd}$ International Conference on Urban Pests 73-82

Dumitrache MO, Paștiu AI, Kalmár Z, Mircean V, Sándor AD, Gherman CM, Peștean C, Mihalica AD, Cozma V (2013) Northern whitebreasted hedgehogs Erinaceus roumanicus as hosts for ticks infected with Borrelia burgdorferi sensu lato and Anaplasma phagocytophilum in Romania. Ticks Tick-Borne Dis 4:214-217

Dziemian S, Michalik J, Piłacińska B, Bialik S, Sikora B, Zwolak R (2014) Infestation of urban populations of the Northern white-breasted hedgehog, Erinaceus roumanicus, by Ixodes spp. ticks in Poland. Med Vet Entomol 28:465-469

Ezenwa VO (2004) Interactions among host diet, nutritional status and gastrointestinal parasite infection in wild bovids. Int J Parasitol 34:535-542

Fielden LJ, Rechav Y, Bryson NR (1992) Acquired immunity to larvae of Amblyomma marmoreum and Ahebraeum by tortoises, guinea-pigs and guinea-fowl. Med Vet Entomol 6:251-254

Földvári G, Rigó K, Jablonszky M, Biró N, Majoros G, Molnár V, Tóth M (2011) Ticks and the city: ectoparasites of the Northern whitebreasted hedgehog (Erinaceus roumanicus) in an urban park. Ticks Tick-Borne Dis 2:231-234

Földvári G, Jahfari S, Rigó K, Jablonszky M, Szekeres S, Majoros G, Tóth M, Molnár V, Coipan EC, Sprong H (2014) Candidatus Neoehrlichia mikurensis and Anaplasma phagocytophilum in urban hedgehogs. Emerg Infect Dis 20:496-498

Gaglio G, Allen S, Bowden L, Bryant M, Morgan ER (2010) Parasites of European hedgehogs (Erinaceus europaeus) in Britain: epidemiological study and coprological test evaluation. Eur J Wildlife Res 56:839-844 
Gern L, Rouvinez E, Toutoungi LN, Godfroid E (1997) Transmission cycles of Borrelia burgdorferi sensu lato involving Lxodes ricinus and/or I. hexagonus ticks and the European hedgehog, Erinaceus europaeus, in suburban and urban areas in Switzerland. Fol Parasitol 44:309-314

Gilles J, Silaghi C, Just FT, Pradel I, Pfister K (2009) Polymerase chain reaction detection of Rickettsia felis-like organism in Archaeopsylla erinacei (Siphonaptera: Pulicidae) from Bavaria, Germany. J Med Entomol 46:703-707

Ginsberg HS, Buckley PA, Balmforth MG, Zhioua E, Mitra S, Buckley FG (2005) Reservoir competence of native North American birds for the Lyme disease spirochete, Borrelia burgdorferi. J Med Entomol 42:445-449

Gray JS, Kahl O, Janetzki-Mittman C, Stein J, Guy E (1994) Acquisition of Borrelia burgdorferi by Ixodes ricinus ticks fed on the European hedgehog Erinaceus europaeus L. Exp App Acarol 18:485-491

Hajipour N, Tavassoli M, Gorgani-Firouzjaee T, Naem S, Pourreza B, Bahramnejad K, Arjmand J (2014) Hedgehogs (Erinaceus europaeus) as a source of ectoparasites in urban-suburban areas of northwest of Iran. J Arthropod Borne Dis 9:98-103

Hornok S, Földvári G, Rigó K, Meli ML, Tóth M, Molnár V, Gönczi E, Farkas R, Hofmann-Lehmann R (2014) Vector-borne agents detected in fleas of the northern white-breasted hedgehog. Vector-Borne Zoonotic Dis 14:74-76

Hubert P, Julliard R, Biagianti S, Poulle ML (2011) Ecological factors driving the higher hedgehog (Erinaceus europeaus) density in an urban area compared to the adjacent rural area. Landscape Urban Plan 103:34-43

Keesing F, Brunner J, Duerr S, Killilea M, LoGiudice K, Schmidt K, Vuong H, Ostfeld RS (2009) Hosts as ecological traps for the vector of Lyme disease. Proc Royal Soc B 276:3911-3919

Keymer IF, Gibson EA, Reynolds DJ (1991) Zoonoses and other findings in hedgehogs (Erinaceus europaeus): a survey of mortality and review of the literature. Vet Rec 128:245-249

Kožuch O, Grešíková M, Nosek J, Lichard M, Sekeyová M (1967) The role of small rodents and hedgehogs in a natural focus of tick-borne encephalitis. B. World Health Organ 36:61-66

Kral B (1967) Karyological analysis of two European species of the genus Erinaceus. Zool List 16:239-252

Krasnov B, Khokhlova I, Shenbrot G (2002) The effect of host density on ectoparasite distribution: an example of a rodent parasitized by fleas. Ecology 83:164-175

Lapini L (1999) Erinaceus concolor Martin, 1838. In: Mitchell-Jones AJ, Bogdanowicz W, Krystufek B, Reijnders PJH, Spitzenberger F, Stubbe C, Thissen JBM, Vohralik V, Zima J (eds) The atlas of European mammals. T \& AD Poyser Natural History Academic Press, London, pp 36-37

Levin ML, Nicholson WL, Massung RF, Sumner JW, Fish D (2002) Comparison of the reservoir competence of medium-sized mammals and Peromyscus leucopus for Anaplasma phagocytophilum in Connecticut. Vector Borne Zoonotic Dis 2:125-136

LoGiudice K, Ostfeld RS, Schmidt KA, Keesing F (2003) The ecology of infectious disease: effects of host diversity and community composition on Lyme disease risk. Proc Natl Acad Sci U S A 100:567-571

Monello RJ, Gompper ME (2010) Differential effects of experimental increases in sociality on ectoparasites of free-ranging raccoons. $\mathrm{J}$ Anim Ecol 79:602-609

Morris P (1973) Winter nests of the hedgehog (Erinaceus europaeus L.). Oecologia 11:299-313

Navarro-Gonzalez N, Verheyden H, Hoste H, Cargnelutti B, Lourtet B, Merlet J, Daufresne T, Lavín S, Hewison AJM, Morand S, Serrano E (2011) Diet quality and immunocompetence influence parasite load of roe deer in a fragmented landscape. Eur J Wildlife Res 57:639-645

Paterson S, Lello J (2003) Mixed models: getting the best use of parasitological data. Trends Parasitol 19:370-375

Patz JA, Daszak P, Tabor GM, Aguirre AA, Pearl M, Epstein J, Wolfe ND, Kilpatrick AM, Foufopoulos J, Molyneux D, Bradley DJ, Working
Group on Land Use Change Disease Emergence (2004) Unhealthy landscapes: policy recommendations on land use change and infectious disease emergence. Environ Health Perspect 112:1092-1098

Pfäffle M, Petney T, Elgas M, Skuballa J, Taraschewski H (2009) Tickinduced blood loss leads to regenerative anaemia in the European hedgehog (Erinaceus europaeus). Parasitology 136:443-452

Pfäffle M, Petney T, Skuballa J, Taraschewski H (2011) Comparative population dynamics of a generalist (Ixodes ricinus) and specialist tick (I. hexagonus) species from European hedgehogs. Exp Appl Acarol 54:151-164

Pfäffle M, Littwin N, Muders SV, Petney TN (2013) The ecology of tickborne diseases. Int J Parasitol 43:1059-1077

Pfäffle M, Bolfiková B, Hulva P, Petney T (2014) Different parasite faunas in sympatric populations of sister hedgehog species in a secondary contact zone. PLoS One 9:e114030

Piper EK, Jackson LA, Bielefeldt-Ohmann H, Gondro C, Lew-Tabor AE, Jonsson NN (2010) Tick-susceptible Bos taurus cattle display an increased cellular response at the site of larval Rhipicephalus (Boophilus) microplus attachment, compared with tick-resistant Bos indicus cattle. Int J Parasitol 40:431-441

Poel JLVD, Dekker J, Langevelde FV (2015) Dutch hedgehogs Erinaceus europaeus are nowadays mainly found in urban areas, possibly due to the negative effects of badgers Meles meles. Wildlife Biol 21:51-55

Råberg L, Graham AL, Read AF (2009) Decomposing health: tolerance and resistance to parasites in animals. Phil Trans Royal Soc B 364: $37-49$

Radzijevskaja J, Paulauskas A, Rosef O, Petkevičius S, Mažeika V, Rekašius T (2013) The propensity of voles and mice to transmit Borrelia burgdorferi sensu lato infection to feeding ticks. Vet Parasitol 197:318-325

Reeve NJ (1994) Hedgehogs. T. \& A.D. Poyser, London

Riley PY, Chomel BB (2005) Hedgehog zoonoses. Emerg Infect Dis 11:1-5

Siuda K (1993) Kleszcze (Acari: Ixodida). II. Systematyka i rozmieszczenie. Polskie Towarzystwo Parazytologiczne, Warszawa

Skuballa J, Oehme R, Hartelt K, Petney T, Bücher T, Kimmig P, Taraschewski H (2007) European hedgehogs as hosts for Borrelia spp., Germany. Emerg Infect Dis 13:952-953

Skuballa J, Taraschewski H, Petney TN, Pfäffle M, Smales LR (2010) The avian acanthocephalan Plagiorhynchus cylindraceus (Palaeacanthocephala) parasitizing in the European hedgehog (Erinaceus europaeus) in Europe and New Zealand. Parasitol Res 106:431-437

Skuballa J, Petney T, Pfäffle M, Oehme R, Harlelt K, Fingerle V, Kimmig P, Taraschewski H (2012) Occurrence of different Borrelia burgdorferi sensu lato genospecies including B. afzelii, $B$. bavariensis and B. spielmanii in hedgehogs (Erinaceus spp.) in Europe. Ticks Tick-Borne Dis 3:8-13

Skuratowicz W (1967) Pchły - Siphonaptera (Aphaniptera): Klucze do oznaczania owadów Polski 29. Państwowe Wydawnictwo Naukowe, Warszawa

Sobrino R, Millán J, Oleaga Á, Gortázar C, de la Fuente J, Ruiz-Fons F (2012) Ecological preferences of exophilic and endophilic ticks (Acari: Ixodidae) parasitizing wild carnivores in the Iberian Peninsula. Vet Parasitol 184:248-257

Sommer RS (2007) When east met west: the sub-fossil footprints of the west European hedgehog and the Northern white-breasted hedgehog during the Late Quaternary in Europe. J Zool 273:82-89

Thamm S, Kalko EKV, Wells K (2010) Ectoparasite infestations of hedgehogs (Erinaceus europaeus) are associated with small-scale landscape structures in an urban-suburban environment. EcoHealth 6:404-413

Wikel SK (1996) Host immunity to ticks. Annu Rev Entomol 41:1-22

Zwolak R, Meagher S, Vaughn JW, Dziemian S, Crone EE (2013) Reduced ectoparasite loads of deer mice in burned forest: From fleas to trees? Ecosphere 4:132 